International Journal of Social Science And Human Research

ISSN(print): 2644-0679, ISSN(online): 2644-0695

Volume 04 Issue 10 October 2021

DOI: 10.47191/ijsshr/v4-i10-47, Impact factor-5.586

Page No: 3000-3006

\title{
Effect of Cooperative Learning Strategy (CLS) On Senior Secondary School Students' Academic Performance in Mathematics in Anambra State, Nigeria
}

\author{
Ezeanyi, Benson Chukwunonso (Ph.D), Fidel-Imoisili, Olukunbi Benedicta ${ }^{2}$, \\ Sowunmi, Elizabeth Bolatito ${ }^{3}$ \\ ${ }^{1}$ Department of Science Education Nnamdi Azikiwe University, Awka, Anambra State, Nigeria \\ ${ }^{2}$ Department of Science Education, Faculty of Education, National Open University of Nigeria \\ ${ }^{3}$ Airforce Secondary School Ikeja, Lagos, Nigeria
}

\begin{abstract}
This study investigated the effect of cooperative learning strategy on senior secondary school students' performance in Mathematics. The study adopted a quasi-experimental research design. The sample for the study consisted of one hundred and forty-four (144) Senior Secondary School two students, selected from Awka Education, Anambra State, Nigeria. The instrument for data collection was Mathematics Performance Test (MPT). The instrument was validated by three experts and had a reliability index of 0.89 obtained through the use of Pearson product moment correlation. Three research questions and three hypotheses were formulated to guide the study. The collected data were analyzed using mean and standard deviation to answer the research questions, while t-test statistics was used to test the null hypotheses at 0.05 alpha levels. The result of the study showed among others that senior secondary school students performed highly when taught Mathematics concepts using cooperative learning instructional strategy; both the male and female students benefitted equally from the cooperative learning strategy. Based on the findings of the study, it was recommended that Mathematics teachers should adopt cooperative learning strategy as an effective learning strategy in order to improve senior secondary school students' academic performance. Also, school management boards should organize workshops, seminars and conferences to expose teachers and students constantly to the use of the strategy for maximum academic output.
\end{abstract}

KEYWORDS: Cooperative learning strategy, Academic performance, Mathematics.

\section{INTRODUCTION}

The introduction of science education into the educational curriculum in Nigeria was a way of solving societal problems such as creating employment opportunities, medical and health care services, technology related issues and many others. Evidence abounds to show that no country can make meaningful development without science and technology. Science is an intellectual activity carried out by scientists designed to discover information about the natural world in which we live and to discover ways in which this information can be organized to benefit human race. In this respect, the primary focus of science is to collect data and the ultimate purpose is to discern order that exist in natural phenomena and happenings around us. Lassa (2020) observed that science is a complex human activity that leads to the production of a body of universal statements called laws, theories or hypotheses which served to explain the observable behaviour of the universe or part of it and which in themselves have predictive characteristics. So many subjects of study make up the science curriculum in Nigerian secondary education of which Mathematics is one of them.

Mathematicians and layman have defined Mathematics in various ways, but all have agreed to the indispensable nature of the subject. They have accordingly described it as the back bone of the society, mother of all sciences and the handmaid to all arts and sciences and thus have recognized its importance and omnipresence. According to Ezeanyi (2021), Mathematics is the study of measurement, patterns, structures, relationship and properties of numbers or quantities, figures and sets. This implies that Mathematics can be considered as a subject and processes, which contains rules of calculations, and processes, which go to help mankind in living a life of comfort and happiness. It contains everything in a very condensed manner and arranged logically which makes it easy for us to group and retain. It is the king of all sciences and queen of all arts, which influence all branches of science in particular. The study of Mathematics is considered to be basic for the development of all other Sciences.

Generally, Mathematics plays important roles in educational advancement but students still lack interest and perform poorly in the subject. Despite the important roles mathematics plays in science teaching and learning, the results of students in mathematics 


\section{Effect of Cooperative Learning Strategy (CLS) On Senior Secondary School Students' Academic Performance in Mathematics in Anambra State, Nigeria}

both at internal and external examinations have consistently shown a very poor performance in mathematics. The trend of performance shows that only about $42 \%$ of the total number of candidates who sat for mathematics examinations passed at credit level and above. This implies that the number of candidates to be admitted into the universities and other tertiary institutions will be less. This also has serious implications for the developing nations aspiring for scientific and technological advancement.

The already erroneous conceived idea about mathematics by most secondary school students in particular and the public in general that it is difficult, needs to be thrashed. No doubt, the evidences of poor academic performance of students in mathematics at the senior secondary school certificate examinations was compounded by conventional methods of instructions adopted by most mathematics teachers, which led to poor students' comprehension of relevant mathematics concepts (Naseem, 2020 \&Okobia, 2017). Extensive studies have been conducted on the effect of method and strategy such as cooperative learning strategy and relative limitations on students' academicperformance and retention (Ajayi, 2020;Glassman, 2018;Simek, 2021). To solve this problem, mathematics teachers will need to develop new teaching strategies that will foster students' involvement in the classroom process. Hence the crust of this study which is to investigate the effect of cooperative learning strategy on students' academic performance in mathematics.

Cooperative learning is a learning strategy that boasts a rich and lengthy heritage. Cooperative learning has existed in several forms throughout history. Meziobi (2018) defined cooperative learning as a way of learning in which students of different ability levels work together in small groups to achieve a goal. It involves the use of a variety of learning activities to improve the understanding of a topic. Students in a group interact with each other, share ideas and information, seek for additional information and make decisions about their discoveries for the whole class. There are four basic elements in the cooperative learning strategy. These basic elements include: (1) small groups must be structured for positive interdependence; (2) there must be face-to-face interactions, (3) individual responsibility and (4) use of interpersonal skills and small groups. It is known that cooperative learning actively involves students in the learning process and seeks to improve the critical thinking, reasoning and problem solving skills of the learner (Johnson \&Stanne, 2018).

Cooperative learning, compared with individualistic or competitive learning, is more complex because it requires students to engage in learning tasks and work together (Steven, 2020). Therefore, social and interpersonal skills, such as listening attentively, questioning cooperatively and negotiating respectfully need be taught, to help students cooperate effectively in the group. In addition, each group member should know how to manage the group, how to make decisions and how to solve conflicts that arise among group members. If these skills are not taught, cooperative learning activities are rarely successful (Babalola, 2016). To coordinate efforts to achieve mutual goals, participants must: (a) get to know and trust each other; (b) communicate accurately and unambiguously; (c) accept and support each other; and (d) resolve conflicts constructively (Steven, 2020). Group processing is defined as reflecting on a group session to help students: (1) describe what member actions were helpful and unhelpful; and (2) make decisions about what actions to continue or change. Group processing helps improve the effectiveness of the members in contributing to the shared efforts to achieve the group's goals via reflection on the learning process (Akinbola, 2018).

Various studies on the effects of cooperative learning on students' academic performance indicated that cooperative learning is not limited to a particular ability level or sex, but to all who engage in it(Ajayi, 2020; Steven, 2020; Tropper and Fall, 2021). Similarly, Glassman (2018); Johnson and Stanne (2018) found that cooperative learning emphasizes status and respect for all members, regardless of gender. More importantly, the study by Anaduaka (2019) found that different cooperative learning strategies can be employed to help low ability students to improve achievement, who had difficulties making success in the traditional classroom. Ajayi (2020) reaffirmed the ability of cooperative learning when used as an instructional strategy to bring about significant improvement in students academic performance in school science subjects and a nonsignificance difference in achievement scores between male and female students in the cooperative learning group. This study will further investigate the effect of cooperative learning strategy on gender and school locations among senior secondary school students in Anambra state. Gender in science according to Ezeanyi (2021) is the classification of the role of male and female in science, technology, engineering and Mathematics (STEM). Significant gender difference in favour of boys as reported by researchers like Carbon (2017)and Catherine (2019) had shown that boys achieve higher in Mathematics than girls. They have also observed that this has often led to the acute shortage of the number of females that gain access to scientific studies and technological training at the tertiary institutions. However, Jacobson and Baribor (2019) found that female students perform better than their male counterparts in Mathematics. Thus the issue of gender-related differences in Mathematics is still a controversy and need to be further investigated in various school locations (urban and rural settlements).

School location refers to the particular place, in relation to other areas in the physical environment (rural or urban), where the school is sited (Odili, 2016). In Nigeria, rural life is uniform, homogenous and less complex than that of urban centers, with cultural diversity, which often is suspected to affect students' academic performance. This is because urban centers are better favored with respect to distribution of social amenities such as pipe borne water, electricity, healthcare facilities while the rural areas are less favored. This is also true in the distribution of educational facilities and teachers. These prevailing conditions imply 


\section{Effect of Cooperative Learning Strategy (CLS) On Senior Secondary School Students' Academic Performance in Mathematics in Anambra State, Nigeria}

that learning opportunities in Nigerian schools differ from school to school. It would appear therefore that students in Nigerian urban schools have more educational opportunities than their counterparts in rural schools. While some studies (Opoh and Akai, 2017; Ruel and Bastiaans, 2018) have shown positive influence, others (Njoku \& Sunday, 2014) have shown negative influence of school location on the students' learning outcome or achievement.

\section{STATEMENT OF THE PROBLEM}

It is worrisome to observe that despite the important roles mathematics plays in national developments, there abound evidence of declining performance in Mathematics education at the senior secondary school level in Nigeria. This abysmal performance can be attributed to wrong use of teaching approaches in Mathematics such as conventional method. This attitude contributed to the ineffective teaching and learning of the subject. Therefore, the present study intends to determine if cooperative learning strategy has varying effect on students' performance in Mathematics.

\section{PURPOSE OF THE STUDY}

The purpose of the study was to examine the effect of cooperative learning strategies on senior secondary school students'academic performance in Mathematics in Awka Education Zone of Anambra State.

Specifically, the study examined the:

1. Mean performance scoresof senior secondary school students taught Mathematics concepts using cooperative learning strategy and those taught using conventional strategy.

2. Mean performance scores of male and female senior secondary school students taught Mathematics concepts using cooperative learning strategy.

3. Mean performance scores of senior secondary school students from urban and rural locations taught Mathematics concepts using cooperative learning strategy.

\section{Research Questions}

1. What are the mean performance scores of senior secondary school students taught Mathematics concepts using cooperative learning strategy and those taught using conventional strategy?

2. What are the mean performance scores of male and female senior secondary school students taught Mathematics concepts using cooperative learning strategy?

3. What are the mean performance scores of senior secondary school students from urban and rural locations taught Mathematics concepts using cooperative learning strategy?

\section{Hypotheses}

1. There is no significant difference between the mean performance scores of senior secondary school students taught mathematics concepts using cooperative learning strategy and those taught using conventional strategy

2. There is no significant difference between the mean performance scores of male and female senior secondary school students taught Mathematics concepts using cooperative learning strategy.

3. There is no significant difference between the mean performance scores of senior secondary school students from urban and rural locations taught Mathematics concepts using cooperative learning strategy.

\section{METHODS}

The design of the study was quasi experimental group design. Specifically, the nonequivalent control group design. The design is considered appropriate because it establishes a cause-effect relationship between the independent variable (strategy) and the dependent variable (performance). This design was adopted because it was not possible to have a complete randomization of the subjects. Thus, intact classes were used as experimental and control groups, since it is not possible to disrupt existing classes in a school. The population of the study consisted of all the 11,253 senior secondary two (SS2) students in Awka Education Zone of Anambra state. A total of 144 senior secondary two (SS2) students was sample for the study. The treatment group consisted of 76 students while the control group were 68 students.

Data was collected through Mathematics Performance Test (MPT), which consist of twenty-five (25) multiple choices objective questions, with options (A-E). The instrument was face and content validated by three experts. The corrections and suggestions made were incorporated in the final draft of the test items. A reliability coefficient of 0.89 was obtained for the study using Pearson product moment correlation.

The experiment was conducted during the normal school periods following the school timetable which lasted for four (4) weeks. The class mathematics teacher who was trained by the researcher using the researcher's prepared eight lesson notes for teaching the control and the experimental groups. The lesson note (CLS) was used for treatment group whereas lesson note on conventional strategy was used for the control group. Before the experiment, subjects in the treatment and control groups were given a pre test. 


\section{Effect of Cooperative Learning Strategy (CLS) On Senior Secondary School Students' Academic Performance in Mathematics in Anambra State, Nigeria}

At the end of the experiment, the researcher with the help of the class mathematics teacher administered the post test to the subjects in the two groups. The pre test and post test were the same except that the colour of the print was changed from black to blue and the item numbers were reshuffled. The scripts were marked and recorded using the same marking guide. Data collected were analyzed using descriptive and inferential statistics. Mean and standard deviation were used to answer the research questions, while the null hypotheses were tested with t-test at 0.05 alpha levels.

\section{RESULT}

Research Question 1: What are the mean performance scores of senior secondary school students taught Mathematics concepts using cooperative learning strategy and those taught using conventional strategy?

Table 1: Mean and standard deviation of senior secondary school students taught Mathematics concepts using Cooperative Learning strategy and those taught with Conventional strategy.

\begin{tabular}{lllllll}
\hline Group & $\mathrm{N}$ & Mean & SD & Mean & SD & Mean gain \\
\hline Experimental & 76 & 48.41 & 11.23 & 69.78 & 9.94 & 21.37 \\
Control & 68 & 48.35 & 11.14 & 55.49 & 10.95 & 6.14 \\
\hline
\end{tabular}

Results in Table 1 showed that the group taught Mathematics concepts using cooperative learning strategy had a higher mean score of 69.78 with mean gain of 21.37 as against the students taught with conventional strategy that had mean scores of 55.49 with mean gain of 6.14. This is an indication that cooperative learning strategy has more effect on senior secondary school students' academic performance in Mathematics than the Conventional strategy.

Research Question 2: What are the mean performance scores of male and female senior secondary school students taught Mathematics concepts using cooperative learning strategy?

Table 2: Mean and standard deviation scores of male and female senior secondary school students taught Mathematics concepts using Cooperative Learning strategy.

\begin{tabular}{lllllll}
\hline Gender & $\mathrm{N}$ & Mean & SD & Mean & SD & Mean gain \\
\hline Male & 32 & 43.48 & 9.47 & 53.18 & 9.63 & 9.70 \\
Female & 44 & 47.08 & 7.63 & 65.18 & 8.47 & 18.10 \\
\hline
\end{tabular}

Table 2 showed that the male students taught Mathematics using cooperative learning strategy had the mean score of 53.18 with mean gain of 9.70 while the female students taught with the same strategy had a mean score of 65.18 with mean gain of 18.10 . This showed that both male and female senior secondary school students taught Mathematics concepts using cooperative learning strategy had a high academic performance, although the mean scores of female are higher than their male counterparts.

Research Question 3: What are the mean performance scores of senior secondary school students from urban and rural locations taught Mathematics concepts using cooperative learning strategy?

Table 3: Mean and standard deviation scores of senior secondary school students from urban and rural locations taught Mathematics concepts using Cooperative learning strategy.

\begin{tabular}{lllllll}
\hline Location & $\mathrm{N}$ & Mean & SD & Mean & SD & Mean gain \\
\hline Urban & 46 & 9.16 & 4.23 & 19.14 & 7.31 & 9.52 \\
Rural & 47 & 8.21 & 2.46 & 14.06 & 2.82 & 5.13 \\
\hline
\end{tabular}

Table 3 showed that the students from urban location taught Mathematics using cooperative learning strategy had the mean score of 19.14 with mean gain of 9.52 while their counterparts from rural locations taught with the same strategy had a mean score of 14.06 with mean gain of 5.13. This indicated that senior secondary school students from urban locations taught Mathematics concepts using cooperative learning strategy had a higher academic performance than those from rural locations.

Hypothesis 1: There is no significant difference between the mean performance scores of senior secondary school students taught mathematics concepts using cooperative learning strategy and those taught using conventional strategy.

Table 4: t-test difference in the mean performance scores of senior secondary school students taught Mathematics concepts using Cooperative learning strategy and those taught using conventional strategy.

\begin{tabular}{lllllllll}
\hline Group & $\mathbf{N}$ & $\mathbf{X}$ & SD & Df & Alpha & t-crit & t-cal & Decision \\
\hline Experimental & 76 & 69.48 & 9.94 & 142 & 0.05 & 1.96 & 9.04 & Reject \\
Control & 68 & 55.49 & 10.95 & & & & & \\
\hline
\end{tabular}




\section{Effect of Cooperative Learning Strategy (CLS) On Senior Secondary School Students' Academic Performance in Mathematics in Anambra State, Nigeria}

The result in Table 4 showed that the t-crit value of 1.96 is less than the t-cal value of 9.04 at 0.05 alpha levels. Therefore, the null hypothesis is rejected. This means that there is a significant difference in the mean performance scores of senior secondary school students taught Mathematics using CLS and those taught with the conventional strategy. Based on the result, students taught with CLS perform better than those taught with the conventional strategy.

Hypothesis 2: There is no significant difference between the mean performance scores of male and female senior secondary school students taught Mathematics concepts using cooperative learning strategy.

Table 5: t-test difference in the mean performance scores of male and female senior secondary school students taught Mathematics concepts using Cooperative learning strategy.

\begin{tabular}{lllllllll}
\hline Gender & $\mathbf{N}$ & $\mathbf{X}$ & SD & Df & Alpha & t-crit & t-cal & Decision \\
\hline Male & 32 & 53.18 & 9.63 & 74 & 0.05 & 1.96 & -1.0 & Accepted \\
Female & 44 & 65.18 & 8.47 & & & & & \\
\hline
\end{tabular}

The result in Table 5 showed that the t-crit value of 1.96 is greater than the t-cal value of -1.0 at 0.05 alpha levels. Therefore, the null hypothesis is accepted. This means that there is no significant difference in the mean performance scores of male and female senior secondary school students taught Mathematics using CLS. Both male and female students performedat an equal rate when taught Mathematics using the Cooperative Learning Strategy.

Hypothesis 3:There is no significant difference between the mean performance scores of senior secondary school students from urban and rural locations taught Mathematics concepts using cooperative learning strategy.

Table 6: t-test difference in the mean performance scores of senior secondary school students from urban and rural locations taught Mathematics concepts using Cooperative learning strategy.

\begin{tabular}{lllllllll}
\hline Location & $\mathbf{N}$ & $\mathbf{X}$ & SD & Df & Alpha & t-crit & t-cal & Decision \\
\hline Urban & 46 & 58.52 & 6.86 & 74 & 0.05 & 1.96 & 4.10 & Rejected \\
Rural & 47 & 41.29 & 4.19 & & & & &
\end{tabular}

The result in Table 6 showed that the $\mathrm{t}$-crit value of 1.96 is less than the $\mathrm{t}$-cal value of 4.10 at 0.05 alpha levels. Therefore, the null hypothesis is rejected. This means that there is a significant difference in the mean performance scores of senior secondary school students from urban and rural locations taught Mathematics using CLS. Based on the result, students from urban locations taught Mathematics concepts with CLS performed better than their counterparts from rural locations taught Mathematics concepts with the same strategy.

\section{DISCUSSION OF THE FINDINGS}

Results in Table 1 showed higher performance mean scores of students taught Mathematics using cooperative learning strategy compared with their counterparts taught using conventional strategy. The result in Table 4 also show a significant difference in the mean performance scores of students taught Mathematics using cooperative learning strategy and those taught using conventional strategy. This finding is in agreement with Jacobson and Steven (2020) who observed that group work could arouse students' learning interest and cultivate their exploring ability and creative thinking and improve their team spirit and social communication skills. Ajayi (2020) noted that cooperative learning can give weak students the opportunity to learn and achieve maximally. Similarly, the study by Anaduaka (2019) found that different cooperative learning strategies can be employed to help low ability students to improve achievement, who had difficulties making success in the conventional classroom. Tropper and Fall (2021) also observed that cooperative teaching strategy allow the students the independence to use his/her mental processes to contribute to knowledge. Glassman (2018) stressing the importance of cooperative learning noted that cooperative learning increase students' academic performance at all ability levels.

Table 2 revealed that the performance mean scores of the male and female senior secondary school students taught Mathematics using cooperative learning strategy were the same. Also, the result in Table 5 revealed that gender is not a significant factor in determining students' performance in Mathematics using cooperative learning strategy. This finding is in agreement with the findings of Ezeanyi (2021), Steven (2020), Tropper and Fall (2021) who found that the cooperative learning is not limited to a particular ability level or sex, but to all who engage in it. Similarly, Jacobson and Baribor (2019) found that cooperative learning emphasizes status and respect for all members, regardless of gender. Ajayi (2020) and Okobia (2017) reaffirmed the ability of cooperative learning when used as an instructional strategy to bring about significant improvement in students achievement in school science subject and non-significance in achievement scores between male and female students in the cooperative learning group. 


\section{Effect of Cooperative Learning Strategy (CLS) On Senior Secondary School Students' Academic Performance in Mathematics in Anambra State, Nigeria}

Result on Table 3, indicated that students from urban locationsperformed better than their rural counterparts after using the CLS. Furthermore, the result on Table 6 indicated a significant difference in the mean performance scores of senior secondary school students from urban and rural locations with students from urban locations performing better. These findings are in agreement with the findings by Carbon (2017); Ezeanyi and Okigbo (2021); Opoh and Akai(2017) that students from urban areas perform better in Mathematics than those from rural areas.These findings were not akin to the findings by Akinbola (2018) and Cathrine (2019) that location of the school had no significant effect on students' mastery of Mathematics concepts. Odili (2016) found that rural and urban students had comparable levels of Mathematics performance. Also, Njoku and Sunday (2014) found that there was significant difference in the use of mathematics skills learning strategies between urban and rural school students. These findings all disagree with the present study. The present findings may be because schools in the rural locations suffer dearth of teaching and learning facilities. Most teachers posted to rural locations abscond and reject their postings thereby leaving the rural schools and their students with insufficient or no teaching staff.

\section{CONCLUSION}

The results of the study showed that students performed high using cooperative learning instructional strategy irrespective of ability level. The results of the study also indicated that both the male and female students benefitted equally from the cooperative learning strategy.

\section{RECOMMENDATIONS}

1. Mathematics teachers should adopt cooperative learning strategy as an effective learning strategy in order to improve students' performance, social interaction skills and foster meta-cognition in students.

2. The school management boards should organize workshops and seminars to expose teachers and students constantly to the use of the strategy for maximum school output.

\section{REFERENCES}

1) Ajayi, K.O. (2020). Effects of 5E learning cycle on students' achievement in Mathematics. Cypriot Journal of Educational Sciences, 7(3), 244-262.

2) Anaduaka, U.S. (2019). Impact of collaborative learning strategies on students' performance in Mathematics in Enugu North Local Government Area of Enugu State, Journal of social sciences, 9(11), 19-28

3) Akinbobola, A.O. (2018). Effects of cooperative learning strategy on academic performance of students in physics, Journal of Research in Education, 3(1), 1-5.

4) Babalola, E. D. (2016). Effective teaching methods, fifth edition. New Jersey: Merrill, PrenticeHall.

5) Carbon, M. L. (2017). Cooperative learning more than just group work. Retrieved 18th March 2014 from corkboardconnections.blogspot.com/

6) Cathrine, M.A. (2019). The disadvantages of tracking and ability grouping: A look atcooperative learning as an alternative. Journal of Studies and Strategies, 7(5), 1-8.

7) Ezeanyi, B. C. (2021). Identification and Remediation of common process errors of senior secondary school students in mathematics in Anambra State. (Unpublished Ph.D. Thesis), Nnamdi Azikiwe University, Awka

8) Ezeanyi, B.C. \&Okigbo, E.C. (2021). Common Process Errors in Geometry Committed by Students from Private and Public Secondary Schools in Anambra State, Nigeria. International Journal of Humanities and Social Studies. 9(7), 4856

9) Glassman, P.I. (2018). A study of cooperative learning in mathematics, writing and readingin intermediate grades: A focus upon achievement, attitudes and self-esteem by gender, race and ability group. Journal of Educational studies and Linguistics, 5(2), 11-18

10) Jacobson, B.N. \&Baribor, V.U. (2019). The effects of teaching techniques on achievement in integrated science: the cooperative learning dimension. Journal of education and training technology, 3(1), 134-143

11) Johnson, R. R. \&Stanne, M.A. (2018). Comparison of computer-assisted cooperative, competitive and individualistic learning. American Educational Research Journal, 2(3), 382-392.

12) Lassa, P.N. (2020). The teaching of mathematics for Nigerian secondary schools. Jos: Fab Anieh Nigeria Limited.

13) Meziobi, K. A. (2018). Combining memory and creativity in teaching mathematics. Journal of Practical teaching and Pedagogy, 25(6), 48-49.

14) Odili, G.A. (2016). Mathematics in Nigeria Secondary schools- A teaching perspective. Port- Harcourt: Anachuna Educational books.

15) Naseem, S.R. (2020). Cooperative learning an instructional strategy. technology. An International Journal of Educational Technology, 1(1), 2231-4105. 
Effect of Cooperative Learning Strategy (CLS) On Senior Secondary School Students' Academic Performance in Mathematics in Anambra State, Nigeria

16) Njok, P.C \& Sunday, D.E. (2014). Socio-cultural factors affecting the teaching and learning of Algebra in Nigeria. Journal of Education Practice, 5 (24), 29-36

17) Okobia, O.S. (2017). The objectives and teaching of Mathematics in Nigeria: Degree of achievement so far. Nigerian Journal of Curriculum Studies. 7(3), 3-37.

18) Opoh, F.A.,\&Akai, K.P. (2017). Evaluation of upper basic social studies students' performance trend in public examination Between 2010-2014 in Cross River State, Nigeria. International Journal of Innovative Education Research $5(3), 42-47$.

19) Ruel, G.A. \&Bastiaans, N. (2018). Free riding and team performance in project education, International Journal of Management Education 3(1), 26-37.

20) Simek, U. B. (2021). Effects of cooperative learning methods on students' academic performances in social psychology lessons. International Journal on New Trends in Education and Their Implications. 4 (3), 09-17.

21) Steven, R.R. (2020). The cooperative elementary school: Effects on students' achievement, attitudes and social relations. American Educational Research Journal 3(2), 31-38.

22) Tropper, J. S. \& Fall, M. R. (2021). Constructive activity and learning in collaborative small groups. Journal of Educational Psychology, 8(4), 06-14. 